One of the great challenges for countries like Tanzania is to produce and enforce policy and regulation to improve road safety indicators. Understanding the behaviour of road users like commercial (called 'Bodaboda') and recreational African motorcycle drivers is an important step towards this goal.

Methods This study is the second part of a traffic psychology project for Bodaboda drivers of the Arusha city in Tanzania. The questionnaire, written in Swahili, was distributed to 513 Bodaboda drivers in December 2016.

The 513 subjects replied to 46 questions to investigate seven different aspects: demographic information, protective equipment, passengers, motorcycle maintenance, police fines and bribes, and driver's crash history.

Results Forty-eight per cent of the respondents had been involved in a crash since they started driving. Perceived crash factors were external: the most frequent cause mentioned was the poor driving skills of other drivers (56.1\%). For $10.5 \%$ of the subjects, crash-avoidance was impossible because crashes are predestined, thus unavoidable.

Conclusion This data gives us important insights into road safety experience and perceptions of professional motorcycle drivers in Arusha, Tanzania. This data, combined with other observational data, is useful to design better policies and regulations in the sector.

\section{D.004 AN UNHELMETED MOTORCYCLIST NOT HOLDING HANDLEBARS - A PHOTOGRAPH IDEA FOR EDUCATION}

Deborah Hilton*. Deborah Hilton Statistics Online [http://sites.google.com/site/ deborahhilton/], ASHWOOD, Australia

\subsection{6/injuryprev-2021-safety.133}

Context A manuscript in the Aust. NZ J of Public Health [2004] by Ozanne-Smith reported that in 2000, 1.2 million deaths resulted from road traffic injury [RTI] with 10 times this number injured. The author states that high income countries have the knowledge, expertise and responsibility for assisting low income countries to counter the growing burden of RTI.

Campaigns in Australia typically have simple, hit home messages with captions overlaid on photos. [Stop, Revive, Survive] is well-known, with accompanying photos displaying red fatigued eyes with the words; tired eyes, yawning, driver fatigue: wake up to the signs.

Process The author noted that in Thailand few motorcyclists wear helmets. Photographs were selected from an array taken by Stephen Hilton, whom won the 2019 Asia Pacific Academic Consortium for Public Health early career network photo competition. A photograph of a young motorcyclist with no helmet, holding one handlebar, while smoking a cigarette was utilised with words overlaid on the image including; Helmet, Handlebars, Headlights.

Analysis A systematic statistical analysis is not possible. Instead the design will be shown to potential travellers being mostly young folk planning travel to Thailand, Bali, Vietnam or Indonesia. Their comments will be gathered and collated with themes identified.

Outcomes Changes in RTI rates are impossible to measure from viewed photographs with overlaid text. Impact on behaviour change being helmet usage maybe ascertained by questioning upon return to Australia.
Learning Outcomes Education may alter behaviour for travellers, while local residents may continue to face barriers such as cost.

\section{E - Data, March 24, 2021}

\section{E.001 IDENTIFYING LOCATION-SPECIFIC INJURY CASES FROM ELECTRONIC MEDICAL RECORD NARRATIVES: THE 'WIPEOUT METHOD'}

1,2William Koon*, ${ }^{2}$ Mendy Losh, ${ }^{2}$ Lauren Tabios. 'University of New South Wales, Sydney, Australia; ${ }^{2}$ Hoag Memorial Hospital Presbyterian, Newport Beach, USA

10.1136/injuryprev-2021-safety. 134

Background Free text narratives in the Electronic Medical Record (EMR) provide rich information, but extracting data is difficult. For emergency department (ED) surveillance and to inform a prevention program for beach-related injury and illness (BRII), we developed and tested the 'Wipeout Method' to query ED EMR narratives in EPIC.

Methods The first of this five-step process involved identifying a cohort of ED BRII cases via lifeguard reports and generating an initial set of search terms based on their EMR narrative. The next four iterative phases involved using the set of search terms, updated for each phase, to query ED EMR records from sequential sample time periods. In each phase, we manually verified BRII cases and analyzed true and false positives of the search using a combination of single word, bi-gram and tri-gram frequencies; gold standard review of high activity days; deep word search of false positive terms; and text classification regression. The set of terms was refined at the end of each stage with the goal of minimizing false positives without compromising precision.

Results The 'Wipeout Method' generated a set of 49 query terms with $75.2 \%$ precision over all available ED EPIC records in our hospital, a 19-month period. We verified 1,605 BRII cases from 2,134 flagged records.

Conclusion This novel method allowed identification of the majority of cases in medical records with the use of minimal resources. The technique is widely applicable to other injury and public health areas for case identification for surveillance and study purposes.

\section{$5 E .002$ FEASIBILITY OF HOSPITAL-BASED INJURY SURVEILLANCE IN NEPAL: A PROSPECTIVE STUDY}

${ }^{1}$ Santosh Bhatta*, ${ }^{2}$ Dan Magnus, ${ }^{1} J u l i e ~ M y t t o n, ~{ }^{3}$ Dhruba Adhikari, ${ }^{3}$ Sunil Raja Manandhar, ${ }^{4}$ Elisha Joshi, ${ }^{4}$ Sumiksha Bhatta, ${ }^{5}$ Sunil Kumar Joshi. 'University of the West of England, Bristol, UK; ${ }^{2}$ University of Bristol, Bristol, UK; ${ }^{3}$ Mother and Infant Research Activities, Kathmandu, Nepal; ${ }^{4}$ Nepal Injury Research Centre, Kathmandu Medical College Public Limited, Kathmandu, Nepal; ${ }^{5}$ Department of Community Medicine, Kathmandu Medical College Public Limited, Kathmandu, Nepal

\subsection{6/injuryprev-2021-safety. 135}

Background Injury surveillance is important for national injury control and prevention initiatives and enables monitoring of progress towards Sustainable Development Goals 3.4 and 3.6. In the absence of a national injury surveillance system in Nepal, we evaluated the feasibility of a model of hospitalbased surveillance. 
Methods An injury surveillance system was introduced in the emergency departments of two hospitals in Makwanpur district. Anonymous data on patients presenting with an injury were collected 24 hours a day between April 2019 and February 2020. A process evaluation involved 14 interviews to explore sustainability of the model.

Results Over 11 months, a total 6942 adult patients with injuries attended the study hospitals. More than half attendees $(64.3 \%)$ were male and most (55.7\%) were young adults (1835 years). Most injuries were unintentional (86.3\%, $\mathrm{n}=5988)$; predominantly road traffic injuries (32.2\%), falls (25.6\%) and animal related harm (20.1\%). The hospital management and clinical staff valued the availability and usefulness of injury data that had been collected from the hospital-based surveillance.

Conclusion A large proportion of the work presenting to these two hospitals is injury related, and potentially preventable. Road traffic injuries are a significant component of the adult injuries. The lack of capacity of hospital staff for collecting injury data is a major barrier for sustaining the injury surveillance system in the longer term.

Learning Outcomes Rich injury data can be obtained by embedding data collectors in emergency departments. Such data can enable monitoring of epidemiological trends. Effective surveillance systems require investment and capacity.

\section{E.003 EPIDEMIOLOGY OF INJURIES AMONG IN-PATIENTS IN NEPAL: A SECONDARY DATA ANALYSIS}

${ }^{1}$ Bidhya Pandey*, ${ }^{2}$ Julie Mytton, ${ }^{2}$ Isabelle Bray, ${ }^{1}$ Sunil Joshi. 'Nepal Injury Research Centre, Kathmadu Medical College Public Limited, Kathmandu, Nepal; ${ }^{2}$ Centre for Public Health and Wellbeing, University of the West of England, Bristol, UK

\subsection{6/injuryprev-2021-safety. 136}

Background Injuries are an important public health issue in Nepal, contributing significantly to the burden of morbidity and mortality. There is no injury surveillance system available, however healthcare service use is routinely reported to central government using the Health Management Information System (HMIS).

Methods To explore the epidemiology of injuries in Nepal we used published national HMIS data on inpatients with injuries from 2009/10 to 2016/17. International Classification of Disease codes were used to classify injury type.

Results Trends varied by injury type. Road Traffic Injuries (RTI) increased from 4.28 (95\% CI 4.03-4.52) per 100,000 in $2009 / 10$ to $10.55(10.17-10.92)$ in $2016 / 17$, while injuries from poisoning almost halved over the same period (from $8.71(8.36-9.06)$ to $4.46(4.22-4.71)$ per 100,000$)$. Inequalities by age and gender were noted; in 2016/17, RTI was the most common unintentional injury affecting adults aged 15-59 years (14.26 (13.70-14.82) per 100,000), while RTIs were almost twice as common in men (13.76 (13.14-14.48) per $100,000)$ than women $(7.66(7.21-8.11)$ per 100,000$)$. In contrast, trends in intentional injuries appear to have fallen over the same time period.

Conclusion In the absence of surveillance data, routine inpatient data can provide evidence of injury epidemiology though underestimates the true burden of disease. Such data may provide evidence to monitor progress towards Sustainable Development Goals (SDG 3.6).

Learning Outcomes HMIS data have not previously been used for injury research in Nepal. The established reporting system offers the potential for basic epidemiological analysis, though the available data fields are limited.

\section{E.004 INJURY MORTALITY TRENDS OVER A DECADE: FINDINGS FROM NATIONAL POPULATION BASED- SURVEY}

Abu Talab*, Aminur Rahman, Salim Mahmood Chowdhury, Shafkat Hossain, AlAmin Bhuiyan, Saidur Rahman Mashreky, Fazlur Rahman. Centre for Injury Prevention and Research, Bangladesh (CIPRB), Dhaka, Bangladesh

\subsection{6/injuryprev-2021-safety. 137}

Backgrounds More than 90\% of global deaths occurred due to injuries in low-and middle-income countries. This paper is focused to reflect the changes in injury mortality and events over the last decade.

Methods Two cross-sectional surveys were conducted in Bangladesh in 2003 and 2016. Multistage cluster sampling method considering probability-proportional-to-size strategy was used in both surveys to obtain the desired sample. Verbal autopsy method was used to ascertain the cause of death.

Results An estimated 70,897 deaths occurred during 2002 due to injuries, whereas, around 108,000 deaths were caused by injuries in all ages 2015 reflected by the death rates 56.0 (95\%CI;64700-77680) and 67.5(95\%CI;93120-122800) respectively. According to survey data suicide, road traffic injury and drowning were the top three causes of injury mortality of all ages. Drowning ranked as the first leading cause $(13.9 \%)$ in 2003 , became third leading cause $(11.7 \%)$ in 2016. RTI ranked as the second leading cause $(11.7 \%)$ and $(12.9 \%)$ in 2002 and 2016 respectively. Suicide rank as the fourth leading cause $(7.4 \%)$ in 2002 , it became the first leading cause $(14.7 \%)$ in 2016. Male were the highest in terms of mortality in both 2002 and 2016, 59.3\%, 63.5\% respectively. A total of $37.8 \%$ death occurred at home in 2003 and $45 \%$ in 2016, followed by hospital and spot death.

Conclusion Injury mortality in Bangladesh was increasing. Suicide, road traffic injury and drowning were the main causes of injury mortality.

Learning Outcomes Government, non-government and development sector need to work together for reducing leading causes of injury mortality.

\section{E.005 INJURY MORTALITY IN SOUTH AFRICA: 2009 VS 2017}

${ }^{1}$ Megan Prinsloo*, ${ }^{2}$ Bianca Dekel, ${ }^{2}$ Shibe Mhlongo, ${ }^{3}$ Nomonde Gwebushe, ${ }^{3}$ Carl Lombard, ${ }^{4}$ Rachel Jewkes, ${ }^{2}$ Naeemah Abrahams, ${ }^{1,5}$ Richard Matzopoulos. ${ }^{1}$ Burden of Disease Research Unit, South African Medical Research Council, Cape Town, South Africa; ${ }^{2}$ Gender and Health Research Unit, South African Medical Research Council, Cape Town, South Africa; ${ }^{3}$ Biostatistics Unit, South African Medical Research Council, Cape Town, South Africa; ${ }^{4}$ Office of the President, South African Medical Research Council, Cape Town, South Africa; ${ }^{5}$ School of Public Health and Family Medicine, University of Cape Town, Cape Town, South Africa

\subsection{6/injuryprev-2021-safety. 138}

Background At 109 per 100000 population, South Africa's injury mortality rate is approximately 1.6 times higher than the global rate of 66.2 per 100 000. Although homicide rates declined since the 1990's, they remain high along with road traffic injury deaths. Two injury mortality surveys for 2009 